\section{O NÃO DE RAIMUNDO SILVA: A PESQUISA NARRATIVA COMO ALTERNATIVA TEÓRICO- METODOLÓGICA PARA ENFRENTAR O CERCO IMPOSTO PELAS POLÍTICAS EDUCATIVAS DO TEMPO PRESENTE}

\author{
THE NO OF RAIMUNDO SILVA: NARRATIVE RESEARCH AS A THEORETICAL- \\ METHODOLOGICAL ALTERNATIVE TO CONFRONT THE SIEGE IMPOSED BY THE \\ EDUCATIONAL POLICIES OF THE PRESENT TIME
}

\author{
EL NO DE RAIMUNDO SILVA: LA INVESTIGACIÓN NARRATIVA COMO UNA \\ ALTERNATIVA TEÓRICO-METODOLÓGICA PARA HACER FRENTE AL CERCO \\ IMPUESTO POR LAS POLITICAS EDUCATIVAS DEL TIEMPO PRESENTE
}

Rodrigo Alberto Lopes*, Elisandro Schultz Wittizorecki*, Vicente Molina Neto*
Palavras chave:

Narração.

Docentes.

História.

Keywords

Narration.

Faculty.

History.

Palabras clave:

Narración.

Docentes.

Historia.
Resumo: Neste artigo apresentamos a pesquisa narrativa como uma estratégia teóricometodológica que, ao mesmo tempo, valoriza o conhecimento dos professores de Educação Física, e os fortalecem na luta contra os desígnios das políticas educativas em formulação no país ao longo do último ano, em especial a MP 746/2016 - "Novo Ensino Médio". Como contraponto, defendemos metaforicamente a formulação de narrativas do não, inspiradas na atitude do revisor de livros Raimundo Silva, personagem do romance "História do Cerco de Lisboa", do escritor José Saramago, que, em seu trabalho, acrescenta um não ao convite feito pelos clérigos portugueses aos cruzados para que os auxiliassem a tomar a cidade do domínio dos "mouros". Para nós, na produção de narrativas alternativas a dominante, sustentadas nas experiências do professorado, residem possibilidades para abrir a história (GAGNEBIN, 2013), reinventado e complexificando conhecimentos, criando alternativas locais e marginais ao "cerco" imposto pelas recentes políticas educativas.

Abstract: In this article we present the narrative research as a theoretical-methodological strategy that values the knowledge of physical education teachers, and strengthens them in the fight against the design of educational policies formulated in the country during the last year, especially the MP 746/2016. As a counterpoint, we metaphorically defend the formulation of non-narratives, inspired by the attitude of book reviewer Raimundo Silva, a character of the novel "The History of the Siege of Lisbon", by writer José Saramago, who in his work adds a no to the invitation made by the Portuguese clerics to the crusaders to help them take the city from the dominion of the "moors". For us, in the production of alternative narratives, based on the experiences of teachers, there are possibilities to open the history (GAGNEBIN, 2013), reinvented and complexifying knowledge, creating local and marginal alternatives to the "siege" imposed by recent educational policies.

Resumen: Este artículo presenta la investigación narrativa como una estrategia teóricometodológica que valora el conocimiento de los profesores de educación física y que los fortalezca en la lucha contra los interés de las políticas educativas en formulación en el país en el último año, sobretodo la MP 746/2016. Como contrapunto, defendemos metafóricamente la formulación de narrativas del no, inspiradas en la actitud del revisor de libros Raimundo Silva, personaje de la novela "Historia del Cerco de Lisboa" del autor José Saramago, que, en su trabajo, decidió añadir un no como respuesta a la invitación del clero portugués para que los cruzados les auxiliasen a tomar la ciudad, bajo el dominio de los "moros". Para nosotros, en la producción de narrativas alternativas a la dominante, sustentadas en experiencias del profesorado, residen posibilidades de abrir la historia (GAGNEBIN, 2013), reinventando y complejificando conocimientos, creando alternativas locales y marginales al "cerco" impuesto por las políticas educativas recientes.
*Universidade Federal do Rio Grande do Sul. Porto Alegre, RS, Brasil. E-mail: rodrigolopes11@gmail.com

Recebido em: 17-02-2017 Aprovado em: 02-03-2017

(c) (1) (8) Licence 


\section{INTRODUÇÃO}

Qualquer história que se pretenda verdadeira, falha em seu propósito. Ela é, desde sua matriz e concepção, apenas mais uma entre tantas perspectivas históricas. Narrar a história, assim, é dedicar-se a resenhar o paradoxo da vida, escrevendo linhas, mobilizando vozes, tentando decifrar o essencialmente indecifrável, "verdadizar" apenas o quanto os limites da voz ou da escrita o permitam. Como nos ensina Veyne (2014, p. 18), há sempre uma "[...] defasagem que separa a experiência vivida da reflexão sobre a narrativa". Sem cair em simplificações pasteurizadas, é dessa tarefa, ao mesmo tempo quixotesca e necessária, que trataremos neste ensaio.

Convictos da nossa incapacidade procuramos, neste ensaio, fazer uso dessas verdades narrativas de modo a compreender um fragmento da história, encontrando fundamentos epistemológicos a garantir respostas, portanto, não mais do que parciais e transitórias. Para sustentar essas já agora reconhecidas limitações, nos implicamos, aqui, em reconhecer e nos apropriamos dos pressupostos teórico-metodológicos da denominada escola narrativista (WHITE, 2014, 2014; RÜSEN, 2016; RICOEUR, 2010a, 2010b). Essa escola compreende 0 ato de narrar como condição para que o homem transforme o tempo em um constructo seu, inteligível, acessivel, mas ainda sim de resultado falho, limitado, e de alcance sempre relativo. Assim, esse ou qualquer outro estudo dessa natureza jamais dará conta de abarcar toda a complexidade do real, cabendo-nos, portanto, nos resignarmos a nossa incapacidade em descortinar essências, ou a totalidade dos fatos, ainda que as busquemos com intensidade. No interior dessa perspectiva cabe a historiadores e a interessados fazer história, assumi-la como poética (poiesis) e prática (WHITE, 2014), e a narração como o modo de executar esse empreendimento teórico e metodológico.

A narrativa, dessa forma, é mais do que dizer ou escrever. É uma possibilidade que nos habilita a produzir versões da nossa incapacidade de entender a existência arquitetando uma metonímia, uma resolução que, travestida de certezas, trabalha para desfazer-se minimamente do incompreendido, dando vozes ou linhas a um desconhecido parcialmente conhecido, que só ganha forma e um nível superior de verossimilhança com o real quando materializado nalgum lugar no tempo, habitando uma espécie de terceiro-tempo, como sugere Ricoeur (2010a). Assumimos o narrar, assim, como um fazer ser, uma forma de dar vida própria ao objeto narrado, de evocar o até então "apenas vivido" no tempo da alma - como defendeu Santo Agostinho, ou mensurado pelos tão pretensiosos quanto limitados instrumentos humanos de confinamento do tempo. Narrar convida ao desafio de tornar mobilizável e próprio um tempo da história que, a partir do dito, escrito e de tantas outras formas de expressar, ousa tentar enfrentá-lo em suas aporias, imponderabilidades, ritmos e circunstâncias.

Para Clandinin e Connelly (2011), a narrativa é o melhor modo de representar e entender a experiência. Por isso, acreditam que essa seria uma forma para compreender como os indivíduos ensinam e aprendem. Ao assim se posicionarem, apresentam a pesquisa narrativa como uma estratégia metodológica qualificada para que pesquisadores e participantes, em colaboração e ao longo do tempo, criem espaços para compreender suas vidas no interior das narrativas dominantes.

Neste estudo, procuramos reconhecer e sustentar a pesquisa narrativa como estratégia teórico-metodológica a nos permitir compreender e resistir aos endereçamentos das atuais 
políticas educativas ao trabalho docente em Educação Física. Consideramos que atualmente vivemos um cenário de apagamento das premissas das políticas educativas democraticamente implantadas pelo Estado brasileiro desde a promulgação da Lei de Diretrizes e Bases da Educação Nacional (Lei no. 9.394/96), sobretudo, a partir do recente pacote de medidas propostas ${ }^{1}$ pelo governo Temer. No nosso caso, optamos por centrar nossos esforços na análise do contexto de influência (MAINARDES, 2006) do qual resulta, entre outros efeitos, a Medida Provisória 746/2016, também conhecida como "Reforma do Ensino Médio". É nossa intenção compreender essa reforma em sua materialidade, porém também como objeto a compor com a história pretérita uma tessitura complexa do que tem significado ser professor de Educação Física no espectro do tempo das políticas educativas contemporâneas. Ao nosso ver, a pesquisa narrativa, ao recuperar o passado de lutas no interior das escolas, cria alternativas locais e marginais próprias para compreender e enfrentar os ditames impostos pelas políticas do tempo presente.

Para esse debate procuramos alinhar o que conhecemos sobre a pesquisa narrativa ao ideário crítico formulado por Walter Benjamin (2013) no que diz respeito ao poder redentor da narração. Desse modo, construímos uma proposição que defende a importância da vida e da voz de personagens ordinários, cotidianos e marginalizados pelo enredo que dá historicidade aos grandes relatos, como elemento de refiguração do tempo. Trata-se de um compromisso político com outras verdades, aquelas que foram solapadas por alguma razão, preteridas, esquecidas, não narradas e que, por isso, guardariam e incubariam outras perspectivas que, embora sondáveis, ainda talvez sejam intangíveis. Aquelas não colonizadas por vozes e fatos e que, portanto, ainda não se fizeram documentos de indelével certeza ou ganharam carimbo de autenticidade. Em resumo, trata-se de creditar à pesquisa narrativa a possibilidade de apresentar-se como uma estratégia viável para, quem sabe, abrir a história (GAGNEBIN, 2012) das políticas educativas contemporâneas. Amparados em Walter Benjamin (2013), acreditamos na pesquisa narrativa como ferramenta capaz de criar histórias a contrapelo, histórias que vislumbrem novos reais e que alcem os professores a condição de protagonistas de renovados caminhos para a compreensão do tempo em seus diferentes extratos.

No que se refere à produção e à implantação de políticas educativas representaria pôr em prática também uma intenção metodológica de Goodson (2013a), que defende a necessidade da criação de linhas transversais à cronologia das políticas educativas (narrativa sistêmica), permeadas de elementos evocados por aqueles que vivem a execução dos seus pressupostos, desvelando tensões e resistências silenciadas. Assim, a pesquisa narrativa, ao reconhecer essas "ressalvas" ungidas desde o chão da escola, dá vida e voz ao que a análise asséptica da narrativa histórica não reconhece: que as políticas são dependentes dos contextos de prática e que os professores, neste caso, seriam maus aplicadores de projetos alheios (HERNANDEZ et al, 2000).

Conhecer e valorizar o que sabem, compreendem e como trabalham os docentes, no interior do curso das políticas educativas, representa uma forma também de valorizar as denominadas "reformas não reformistas" (APPLE, 2000, p. 169). Essas, embora não tenham caráter de oficialidade, estão, localmente, comprometidas em "[...] defender práticas

\footnotetext{
1 Para compreender as recentes proposições de mudanças na Lei de Diretrizes e Bases da Educação Nacional um elemento central é a recente ruptura na governabilidade do país alterada pelo conjunto de forças do parlamento. Em 31 de agosto de 2016, o Senado da República por 61 votos a favor e 20 contra, sacramentou o golpe parlamentar, afastando Dilma Roussef da presidência da República para a qual foi eleita com aproximadamente 52 milhões de votos. A assunção desse conjunto de forças políticas redefine a hegemonia dos poderes da República e o protagonismo da cena política nacional.
} 
democráticas contra a ganância das lógicas econômicas em expansão", impedindo o fatalismo em relação a derrotas em âmbito global. É preciso, portanto, que reconheçamos que lutar nas escolas também significa lutar na sociedade. Essas lutas, portanto, não são epifenomenais (APPLE, 2003). Elas podem produzir efeitos significativos na melhoria da qualidade de ensino, garantia de justiça social, maior democratização do espaço escolar público ou tantas outras batalhas a serem reconhecidas.

Por não acreditarmos neste fatalismo entre promulgação, implantação e execução de uma política pública, concordamos com Ball (1994) e Mainardes (2006) quando afirmam que as políticas educativas se materializam, na realidade, ante traduções eminentemente locais. São postas em prática desde um somatório híbrido de outras intenções paralelas, práticas artesanais próprias e outros textos, mesmo que, eventualmente, de matriz teórica, epistemológica ou ideológica contrastante com os preceitos dos ordenamentos legais em vigor. Em nossa visão, as práticas cotidianas construídas nos próprios espaços educativos, portanto, influenciam direta e substancialmente a recepção e o rearranjo que as políticas educativas ganham em âmbito local, e, por isso, também são merecedoras de atenção e de estudos que as revelem, fortaleçam e exponenciem. Acreditar que as políticas educativas mantenham, durante todo o seu ciclo, desde o contexto de influência até 0 de prática, uma essência, nos parece um pressuposto teoricamente falho, ao menos em regimes minimamente democráticos como ainda é o nosso. A "química" que perfaz esse processo carrega consigo, em sua composição, uma espécie de "fuligem", um resto deixado por outras experiências tanto macro quanto micropolíticas. Estas políticas residuais, ao nosso ver, alteram em maior ou menor proporção a essência de qualquer política implantada, fazendo com que, na prática, ela simplesmente não exista ou se reconfigure substancialmente. É papel, portanto, de uma história revisitada e recontada, traçar um percurso que amplie o enfoque analítico, interpretado para além simplesmente da política em curso, ou condicionada a avaliar os efeitos práticos que esta pretenda instaurar. É por isso que para enfrentar o tempo presente entendemos ser importante recorrer ao passado, revisitando as teorias e práticas que viabilizaram a constituição identitária do ser-docente. Mesmo que localmente, conjura-se um novo tempo. Tempo desfeito da linear cronologia que transforma o curso natural dos grandes acontecimentos em verdade e história. Um tempo permeados por nãos, que contestem verdades e inspirem outras poiesis.

A partir desse não, utilizamos alegoricamente nesse estudo as premissas de um livro do autor português José Saramago, intitulado "História do Cerco de Lisboa", como inspiração para pensar sobre a fragilidade da construção da história enquanto materialidade das políticas educativas. Nessa obra, Saramago apresenta a trajetória de Raimundo Silva, um revisor de livros, que, certo dia, desconfiado, e de alguma forma convicto, das inverdades que o livro em que trabalhava parecia se basear para descrever a tomada de Lisboa dos mouros, resolveu acrescentar, por conta e risco, um não como resposta dos cruzados ao pedido de ajuda dos clérigos portugueses a sua iniciativa de assumir o controle da cidade. A ação foi vista pelos editores do livro como uma afronta, afinal de contas, esse importante relato histórico estava fundamentado em fontes de indiscutível relevância, provenientes de escritores que tiveram acesso privilegiado aos textos consagrados pelo tempo e pela Grande História Portuguesa. Portanto, para os editores não caberia a Raimundo, um simples revisor, tentar mudar o que existe, o que sempre foi verdadeiro, ainda mais depois de tantos anos. Acontece que, por intermédio de uma executiva da editora, o revisor foi convidado a dar vida a esse não, (re) escrever a História do cerco, dando a ela o caminho e os contornos que julgara correto quando 
ousadamente resolveu borrar os fatos, dizer que aquilo que o curso do tempo consagrou não era (ou poderia não ser) como se reproduziu. Morador de Lisboa dos tempos atuais, Raimundo viu, na sua vida cotidiana e nas ruas pelas quais corriam memórias e evidências, a possibilidade de compreender aquela história de outra forma, a partir do seu ponto de vista. Além disso, Raimundo, o novo autor dessa história, acabava por conferir, em sua escrita, o protagonismo a dois novos personagens, estes, até então, irrelevantes para o referido acontecimento: Mogueime e Ouroana - ele soldado português e ela concubina. É da natureza desta ação, a do não que aquele revisor deu à história oficial, e aos acontecimentos dele resultantes, que partiu a inspiração para dar conta do desenho e dos fundamentos políticos que estruturam o presente artigo. Essa alegoria representa, ficcionalmente, como nós materialmente encaramos a escrita da história e as suas poiesis narrativas. Mais do que adorno estético, essa metáfora simboliza muito da nossa história como grupo de pesquisa², nossos topóis investigativos mais característicos, o nosso "jeitão" de fazer pesquisa (WITTZORECKI et al, 2006). Guardadas as devidas proporções fáticas, é ela que nos mobiliza a tomar a frente na luta, especialmente em escala local, ante a plêiade emergente de enfrentamentos e resistências impostas e porvir.

Ainda que aprender sobre um processo em deflagração, em que seus desdobramentos ainda não foram completamente revelados, tampouco possíveis de serem devidamente previstos, seja um risco, nos autorizamos a amparar este estudo nos fundamentos teóricometodológicos da denominada História do Tempo Presente. Decidimos enfrentar esses riscos por acreditar em uma das vantagens que Delgado e Ferreira (2014) apregoam: a possibilidade ofertada ao pesquisador, ao viver organicamente a potência do que investiga, de assumirse como parte do próprio estudo, como agente de afetação, capaz de sentir e, ao mesmo tempo, agir sobre o investigado. Nosso compromisso não está somente em compreender esses tempos, mas também ajudar a revelar e antecipar seus sentidos incipientes ou mesmo impensáveis, oferecendo alternativas de enfrentamento. Nos reconhecemos e nos autorizamos, assim, a sermos pesquisadores-autores do texto e a nos fazermos presentes em suas próprias linhas. A história do tempo presente privilegia, como estratégia de coleta de informações, a vida e a voz dos reais e atuais habitantes do cotidiano, aqueles que vivem, mas também, potencialmente, são capazes de alterá-lo, desde as suas ações no próprio enredo histórico que vivem. Assim, privilegia o testemunho, cuja pertinência está no caráter, ao mesmo tempo crítico e ativo das fontes (DELGADO; FERREIRA, 2014; FERREIRA; AMADO, 2006). Denominamos a história desse tempo presente como "história do cerco", pois entendemos estar diante de um processo de desmonte, patrocinado pelo Estado, da educação como bem público, cujos efeitos implicam diretamente na (previsível) precarização da qualidade da educação e na diminuição de perspectivas emancipatórias de futuro a crianças e adolescentes de baixa renda.

\section{DA HISTÓRIA COMO UMA NARRATIVA EM CONSTRUÇÃO À PESQUISA NARRATIVA: PRESSUPOSTOS TEÓRICO-METODOLÓGICOS}

Como alicerces teóricos aos propósitos fundantes deste ensaio, nos pareceu profundamente mobilizadora a tese do filósofo Paul Ricoeur (2010a, 2010b), a de que 0 tempo se torna humano à medida que é articulado de forma narrativa. Se o autor estiver correto, pensamos: seriamos nós, então, potencialmente, narradores-artífices do tempo,

2 Grupo de Grupo de Estudos Qualitativos Formação de Professores e Prática Pedagógica em Educação Física e Ciências do Esporte (F3PEFICE), vinculado ao Programa de Pós-Graduação em Ciências do Movimento Humano da Universidade Federal do Rio Grande do Sul (http:// www.ufrgs.br/f3p-efice). 
entes habilitados a produzir-Ihe aporias, a transformar o rio do tempo em lagoa, a fazer deitar horizontalmente a ampulheta das horas, dando repouso às areias que até então, resignadas, apenas cumpriam obcecadamente seu curso até outro bordo?

Para produção deste artigo partiremos da premissa de que sim, Ricoeur está correto. Fazemos isso altamente convictos, porém, de que estamos, na realidade, não mais do que abraçando uma entre muitas tantas narrativas que versam sobre o significado de história, a que nos trouxe como autores as alternativas que entendemos melhor dar conta de garantir algum nível de compreensão ao investigado e também persuadir nossos eventuais e hipotéticos leitores.

Ricoeur (2010a) defende o primado da compreensão narrativa como explicação historiográfica. Segundo o autor, a forma própria do discurso histórico sempre foi a narrativa, o que, por sua vez, não é incompatível com a abordagem histórica ancorada em documentos. Portanto, compreender a história como narrativa contraria a história estrutural porque dá a devida dimensão à temporalidade dos homens, aqueles que, em seu próprio viver e fazer-se (sujeito, profissional, cidadão, indivíduo, mulher/homem), se reconhecem, a despeito de descrições amplas, categorizações apriorísticas e pelo primado da quantificação. O intento de Ricoeur era o de retirar do curso da história o seu caráter determinista, sem, com isso, desconsiderar o seu caráter lógico, haja vista a necessidade de um encadeamento com base em evidências, em fatos verdadeiramente ocorridos no passado. A narrativa, assim, surge, para o autor, como uma prática intrinsecamente vinculada à teoria da história: para que essa torne o vivido inteligível é preciso articular o tempo, a ordem cronológica e a composição da narrativa.

Para Ricoeur (2010a), as diversas tramas que são inventadas — no dia-a-dia, na ficção literária ou na construção historiográfica — têm o papel primordial de ajudar a configurar nossa experiência temporal confusa e disforme. Assim, quando o autor sugere que o tempo só pode ser compreendido de maneira prática, através do ato de narrar, na verdade sugere que, na história, e também na vida, as decisões são tomadas na própria trama, e não antes dela ou em algum ponto exterior, em um mundo predeterminado, atemporal.

Ao se dedicar a estudar a história nessa perspectiva teórica, Ricoeur (2010a) defende que esta ocorre mediante uma refiguração do tempo, ou seja, do remanejamento da experiência temporal graças ao texto em que se situa. Assim, os historiadores reconstroem um dos passados possíveis, sendo sua escrita dependente dos rastros deixados por eles, comprovados a partir de eventos, documentos, textos, memórias. Representa uma possibilidade poética de articular mediações entre os eventos dispersos, produzir contestabilidade aos cronologicamente sequenciados; permite reinscrever autores e atores na trama contada, instando reinventados objetivos, causas-efeitos, arcos, condições e circunstâncias, inclusive sugerindo e validando resultados inicialmente inesperados (PELLAUER, 2010).

Mesmo que a narração do tempo, conforme pontua Ricoeur no último tomo de Tempo e Narrativa (2010b), teça caminhos promissores e esperançosos ao utópico desejo humano em poder contê-lo e apressá-lo, não evita, todavia, sua inescrutabilidade, pois a relação entre tempo humano e tempo cronológico continua um enigma, impenetrável, incomensurável. A narrativa trata-se de um tempo, portanto, reconfigurado e não o próprio tempo. Mesmo todo o esforço de apreensão do tempo - cronômetros, relógios, horas, dias, ou a própria narração - é insuficiente, pois dificilmente poderá superar definitivamente as diferenças existentes entre 0 sentido e a experiência, entre o vivido e o que é medido, o que é pensado e o que é escrito. 
Como espécie de ponto de chegada a sua concepção de história, tempo e narração, Ricoeur defende possibilidades de vislumbrar uma espécie de hermenêutica da consciência histórica "no intuito de reencontrar uma dialética entre o passado e o futuro, e as trocas entre eles no presente (RICOEUR, 2010b). Essa dimensão privilegiaria fazer a história e implicaria responder afirmativamente à seguinte questão formulada por ele (RICOEUR, 2010b, p. 353): "[...] não poderia o presente ser o tempo da iniciativa, isto é, o tempo em que o peso da história já feita é depositado, suspendido, interrompido, e em que o sonho da história ainda por fazer é transfigurado em decisão responsável?" O tempo presente, portanto, ao ser o tempo da ação, onde a história do passado e do futuro também são renovadas e reinterpretadas, confere as pesquisas que privilegiam o tempo em que se vive, reconhecendo nas narrativas pessoais que procuram explicar o tempo tornando-o humano, uma possibilidade ilimitada de aberturas de possíveis.

Essas pistas nos levam a procurar os ombros de outro autor que também valoriza a narrativa como espaço de produção da história e de mobilização de novos sentidos para enfrentá-la. Trata-se de Walter Benjamin, para quem a história pode ser constituída de uma natureza poética e multiforme. Sustentar tal posição, segundo ao autor, é reconhecer alternativas à história das estruturas e de largo espectro, alçando-a a um terreno de possibilidades, onde o novo sempre é possível. Segundo Gagnebin (2013), Benjamin nos convoca a lutar pela construção de uma história aberta.

Em sua teoria da história, Benjamin (2013) nos incita a um olhar historiográfico comprometido com os oprimidos, os que foram silenciados ou desmerecidos pela "escrita conhecida", o que também agrega à sua teoria um estatuto político. Trata-se, assim, de construir uma história escovada a contrapelo, que faça jus a novas histórias, a novas memórias e também à redenção daqueles que perderam batalhas passadas. A proposta significa recusar a identificação e a empatia com os heróis oficiais da história: é preciso, segundo o autor, pensar a história sob um ponto de vista poético, nomeando homens e mulheres para salvá-los ${ }^{3}$ do esquecimento. Esse aspecto reitera que a história - para que faça justiça aos oprimidos precisa ser recriada.

A construção de narrativas históricas a contrapelo, para Benjamin (2013), deve ser permeada por cesuras (ou rupturas) que inibam a sequência cronológica da história, de modo a impedir que o curso do tempo continue a garantir intermitência às vitórias dos já vencedores. Constitui-se em um elemento para complexificar e alargar o espectro do tempo na história, dando também aos vencidos a chance de dizê-la, contestá-la semelhante ao que fez Raimundo, o personagem de Saramago, que nos inspira neste texto. A cesura, neste contexto, representa os "nãos", espaços poéticos, em que os emudecidos pela história podem fazer uso da palavra para questionar o seu curso e, desde este ponto, recontá-la a seus modos, de acordo com os preceitos pelos quais lutam ou lutaram. Uma das funções da cesura, na perspectiva de Gagnebin (2013), é impedir simples causalidades históricas, opondo-lhe uma relação de intensidade entre dois ou mais acontecimentos, cristalizando uma significação inédita.

A história aberta, do ponto de vista político, admite que a história comporte e suporte ainda outras possibilidades revolucionárias e emancipadoras. Isso quer dizer que existem "saídas" para as certezas do "caminho liso da história" (FARGE, 2015). Isso significa entender

3 Embora tal expressão soe deveras redentora e não sejam essas as intenções que propomos, decidimos mantê-la, neste estudo, de modo a ser fiel à escrita e às premissas do autor sobre o qual estamos nos debruçando nesse momento: Walter Benjamim. 
e defender que a versão da história que conhecemos, embora triunfante, não era e nem precisa continuar a ser a única (SIRINELLI, 2014). Da mesma forma, se a história é aberta, se 0 novo é possível, é porque o futuro também não é conhecido antecipadamente. Evita-se, assim, pensar a história como um produto de circunstâncias naturais (progresso econômico, técnico e científico), como se o seu curso fosse uma regra e uma condição para a determinação do que é político e social, e os seus efeitos econômicos como incontroláveis e irremediáveis

O conceito de história como aberta exige um olhar que a interprete e reinterprete a memória. Para Gagnebin (2012), isso requer aprender a lidar com os rastros que, no interior da perspectiva benjaminiana, representa a própria prática historiográfica. 0 pesquisadorhistoriador imbuído de uma historiografia crítica deve se empenhar em indícios que escapam ao controle de uma versão dominante da história, trazendo interrogações, contradições e contestações. Esses rastros geralmente são pouco visíveis, pois não se destacam; muitas vezes são contrastantes aos sentidos em vigor em dada época e praticados por determinado coletivo. Ademais, esses rastros também não são facilmente perceptíveis, pois parecem aleatórios, fragmentados, inconsistentes para representar uma história.

De acordo com os conceitos apresentados até então, nos interessa saber: quais reformas não-reformistas os professores de Educação Física empregaram em seus exercícios profissionais no curso das políticas educativas pós-LDB/1996? De que modo estas poiesis podem servir-lhes de instrumentos de luta para enfrentar o cerco imposto pelas políticas educativas do tempo presente? Quais foram os momentos em que esses professores se puseram na contracorrente? Quais versões subversivas das políticas educativas ganharam vida em suas aulas ou em sua experiência política? Rastros dessas ações e reações, pensamos, potencialmente podem recontar a história, podem inserir novos elementos no que sabemos, podem explicar os sentidos do que tem significado ser docente de Educação no contexto das políticas educativas. Podem, ao nosso ver, permitir aos professores construir, desde a narração e significação das suas próprias histórias, estratégias para enfrentar o cerco imposto pelas políticas educativas do tempo presente, especialmente em âmbito local.

\section{O CONTEXTO DE INFLUÊNCIA DAS POLÍTICAS EDUCATIVAS NO TEMPO PRESENTE: A "HISTÓRIA DO CERCO" IMPOSTO À EDUCAÇÃO (FÍSICA)}

Neste artigo, nos dedicamos mais do que a avaliar especificamente uma política educativa; estamos interessados em um contexto. E é desde a sua caracterização que sustentamos as nossas formulações teóricas e metodológicas. Sob o ponto de vista das políticas educativas do tempo presente, acreditamos estar vivendo um gradativo apagamento das conquistas históricas formalizadas em diferentes ordenamentos legais recentemente implantados.

Vivemos hoje 4 um tempo-espaço em que novas políticas estão sendo discutidas e validadas, cenário denominado por Ball (1994) e Mainardes (2006) como contexto de influência para a produção de novas políticas. Esse é um período em que grupos se articulam para influenciar a definição da linha na qual pautam seus debates e o caminho social a ser percorrido. $O$ resultado é um equilíbrio sempre provisório e frágil de forças a atender diferentes interesses.

4 Dezembro de 2016. 
Segundo Libâneo, Oliveira e Toschi (2009) as políticas educacionais contemporâneas precisam ser compreendidas dentro de um quadro que as relacione com as transformações econômicas, políticas e culturais que orientam o cenário global. A educação pública é afetada por liames de variadas formas, fazendo com que ela, nos últimos tempos, tenha estado, invariavelmente, a serviço da economia. Os programas educativos e as reformas, em uma perspectiva ampliada, configuram-se como mecanismos redentores quanto ao processo de desenvolvimento econômico. Nesse cenário, emergem com privilegiado destaque as orientações de organismos globais multilaterais com força de indução política. Esses organismos são, em verdade, genuínos representantes dos interesses do capital financeiro internacional, destacando-se como especialistas frente ao "anseio inquestionável" do banalizado e cínico atual emprego do termo qualidade da educação.

Tudo isso converge para um reordenamento sistemático das prioridades do Estado, subordinando a democracia aos interesses do poder econômico (McCARTHY et al, 2011) e também ao atendimento das agendas conservadoras (APPLE, 2003). Nesse cenário, as instituições democráticas diminuem seus poderes de influência, sendo substituídas pelas demandas do mercado. Ocorre, assim, uma espécie de "constitucionalização do neoliberalismo" (ROBERTSON; DALE, 2011). O sistema escolar, por exemplo, volta-se para o atendimento dos humores da economia e do mercado, valendo-se de máximas e jargões de natureza thatcherian $a^{5}$ que disseminam disfarçadamente suas, via de regra, impopulares intenções, como as de que não há alternativa, não há lugar para todos, e de que é preciso reformar para melhorar.

Apesar da sempre latente interferência de interesses do capital global e de documentos indutores de políticas intimamente ligados a eles, desde 1996, com a implantação da Lei de Diretrizes e Bases da Educação Nacional, se estabeleceu um marco legal que, fundamentado nos princípios de gestão democrática, igualdade de condições para o acesso e permanência na escola e garantia do padrão de qualidade, vinham se desdobrando em um leque de documentos e orientações subsequentes que contavam com significativa participação da sociedade civil. Em que pese todos os avanços e retrocessos, interferências e silenciamentos, esse foi um período de profundos e intensos debates. As camadas populares foram, em alguma medida, ouvidas e viram alguns de seus pleitos formalizados como política educativa pública.

$\mathrm{Na}$ esteira da LDB podemos destacar as discussões que balizaram a implantação dos Parâmetros Curriculares Nacionais (1998a), das Diretrizes Curriculares para a Educação Básica (1998b, 20126), dos planos nacionais, estaduais e municipais de educação e, por fim, o do inacabado processo de construção da Base Nacional Curricular Comum $(2015,2016 a)^{7}$. 0 processo de democratização do acesso e a garantia da qualidade de ensino, mesmo que incompleto e com limites muitas vezes interpostos pelo cenário macroeconômico global neoliberal, ainda nos permitia perspectivar uma escola pública como almejávamos. Hoje, todavia, o modelo de educação que defendemos sofre, agoniza, e os horizontes que se revelam não parecem nem um pouco alvissareiros.

5 Refere-se aos princípios econômicos neoliberais e neoconservadores implantados pela primeira ministra inglesa Margaret Thatcher (19791990). Em suas políticas valia-se basicamente de privatizações, de maior atenção aos interesses do mercado e de desmantelamento de políticas de bem-estar social.

6 http://portal.mec.gov.br/docman/julho-2013-pdf/13677-diretrizes-educacao-basica-2013-pdf/file

7 Há entre os trabalhadores da educação em geral e o professorado de Educação Física certas incertezas e perplexidades, porque faz uma série de alterações importantes na LDB, remete seus encaminhamentos para os Sistemas Estaduais de Educação e para a Base Nacional Comum Curricular (BNCC), o que é bastante problemático, dado que os Sistemas Estaduais de Educação estão colapsados e a BNCC ainda está na fase de Revisão da segunda versão, portanto, inacabada para o uso pelos Sistemas Estaduais de Educação. http:// basenacionalcomum.mec.gov.br/\#/site/inicio 
$O$ fato é que os tempos se aceleraram de tal forma que anos e anos de processo democrático de construção de políticas públicas colapsaram com o novo governo brasileiro, iniciado em maio de 2016. Direitos sociais conquistados com esforços de muitas mãos estão sendo subtraídos a velocidades difíceis de acompanhar e prever, processo contra o qual tem sido difícil de se mobilizar, quanto mais almejar evitar. Os espaços de diálogo afastam-se cada vez mais da realidade que vivem os artífices do cotidiano da educação - professores e estudantes - para aproximar-se dos interesses dos detentores do capital, grandes empresários e representantes de setores conservadores da sociedade.

Desde então o processo de gênese e implantação das políticas públicas no país vem ocorrendo partir de mudanças apressadas e oportunistas na Constituição Federal, por exemplo a PEC $55^{8}$, que imobiliza os investimentos em Educação, ou por meio de medidas provisórias, como a Medida Provisória (MP) 746 - reforma do Ensino Médio. Os debates que a sociedade civil vinha travando para a construção de um novo ensino médio, por exemplo, materializado inclusive em experiências promissoras, com o ensino politécnico na rede estadual de ensino do Rio Grande do Sul (2011), são sublimadas. É como se nunca houvessem existido, renunciadas em prol de medidas autodeclaradas "duras, mas necessárias", mesmo que nesta afirmativa subjaza, no nosso entendimento, a concepção de que são necessárias para alguns privilegiados e duras para a grande parcela da população nacional, os mais pobres. Para Apple (2003, p.10), "[...] toda a esfera pública tem sido posta em questão" pela modernização conservadora.

Especificamente quanto ao "novo ensino médio", a MP 746 representa uma proposição elaborada a partir de pressões de setores socialmente influentes ${ }^{9}$, e que já foi reconfigurada por muitas emendas impostas ao texto original. 0 texto da medida, em sua raiz, possui uma forte inclinação em priorizar, sobretudo sob o ponto de vista curricular, a construção de conhecimentos técnicos-instrumentais que garantam competências profissionais não mais do que mínimas para exercícios de funções que o mercado demanda. Essas estariam vinculadas à oferta de mão de obra mais rentável aos empresários detentores de influência sobre o capital. Para Frigotto (2013), no interior dessa perspectiva as competências ensinadas na escola passam a pretender garantir, quando muito, a empregabilidade, desde que essas competências sejam deliberadas e validadas pelo próprio mercado. Segundo Frigotto (2013, p. 68), "[...] o empregável tem a qualidade mercantil de ser flexível e permanecer com garantia de emprego apenas enquanto funcional ao seu empregador".

O ensino médio, assim, privilegiaria, conforme seu texto (BRASIL, 2016b), via significativo aumento de carga horária, Língua Portuguesa e Matemática, componentes curriculares considerados chave para o desenvolvimento do perfil de cidadão e trabalhador a ser formado pela educação pública do país. Excetuando-se os dois componentes curriculares citados e também a Língua Inglesa, os outros seriam flexibilizados, tornados optativos ao longo do período que o estudante se dedicaria a essa modalidade de ensino. Seriam cursados apenas caso o estudante opte pelo caminho ao qual este componente está vinculado (as quatro áreas de conhecimento previstas na LDB, Linguagens, Matemática, Ciências da natureza e Ciências Humanas, mais o novo ensino profissionalizante). Os estudantes seriam atendidos em turno

8 Projeto de Emenda Constitucional aprovado no Senado Federal em 13 de dezembro de 2016, que alterou, em claro retrocesso a direitos constitucionais garantidos, as disposições constitucionais transitórias para instituir um novo regime fiscal - "congelamento" dos gastos primários do governo por 20 anos - desvinculando a receita da União das despesas correntes e investimentos, deixando de lado o debate educacional e acadêmico que antecede o estabelecido no Plano Nacional de Educação (PNE) 2014-2034, Lei nº 13.005, de 25 de junho de 2014 (BRASIL, 2014). Direita e Centro-Esquerda, Setores da Classe Média e Setores Fundamentalistas Cristãos-Evangélicos (APPLE, 2003). 
integral (o que no nosso entendimento não significa que os estudantes participarão de tempos e espaços escolares verdadeiramente comprometidos com a educação integral, como defende o governo), e nesse tempo adicional seriam oferecidas atividades pretensamente condizentes com a área escolhida pelo estudante e o currículo a ela vinculada. 0 estudante poderia optar por cursar alguns componentes e não outros, sob a alegação de que assim teria liberdade para escolher seus caminhos, dependendo dos seus interesses profissionais futuros, e também adequando-os a sua vocação $0^{10}$, termo esse que tem sido veiculado nas campanhas publicitárias do Governo Federal, em veículos de imprensa diversos. Nesse desenho, o estudante torna-se um empreendedor de si mesmo (McCARTHY et al., 2011), e, como tal, assume implicitamente também como seus os ônus pelos possíveis equívocos que essa decisão venha a produzir. Esse empreendedor, assim, é potencialmente também um algoz de si mesmo pois a previsível precarização da sua formação profissional, torna-se um resultado unicamente de suas más escolhas individuais, e não de um descompromisso do sistema educativo para com ele.

Para o exercício docente, o "novo ensino médio" também prevê a possibilidade de as redes de ensino público contratarem pessoas consideradas detentoras de notório saber (BRASIL, 2016b) para que ministrem aulas, mesmo que não tenham trilhado um percurso formativo condizente com o exercício docente, e sem que, necessariamente, sejam portadoras de diplomas de licenciatura (ensino superior) ou magistério (ensino médio).

Para a educação física, especificamente, o cenário se apresenta obscuro, semelhante ao que ocorre com outros componentes curriculares caracterizados epistemologicamente pela expressividade e potencialidade crítica - artes, sociologia e filosofia. Esses componentes estão excluídos de sua obrigatoriedade ${ }^{11}$. Vê-se, desde um movimento unilateral, ruir o que entendemos serem conquistas que, por muito tempo, foram lutadas, e que com grande esforço conquistadas. Falamos, por exemplo da sua obrigatoriedade ao longo de toda a educação básica, do status de componente curricular, e da sua necessária vinculação às propostas político-pedagógicas das escolas (BRASIL, 1996). Falamos também, do fortalecimento, via dispositivos legais subsequentes (BRASIL, 1998a, 1998b, 2004, 2012, 2015, 2016a) da educação física escolar como componente vinculado à área das linguagens e suas tecnologias, fundamentado em especificidades crítico-expressivas. Além disso, vimos o conceito de cultura corporal do movimento como objeto epistemológico fundante da educação física escolar ser consolidado ao longo das duas últimas décadas, se fazendo presente e melhor compreendido ao longo do curso de implantação das referidas políticas, mesmo que estivéssemos como professores, na prática, vivendo ainda a paradigmática mudança entre o não mais e 0 ainda não, conforme descreve o estudo de Gonzalez e Fensterseifer (2009).

Assim, se é bem verdade que o ainda não estivesse em um processo demasiado longo para tornar-se, enfim, um agora-sim, e que a eficiência desse modelo de educação física estivesse desde sempre sob o signo da descrença e da contestação por parte de outros campos teóricos (perspectivas ligadas estreitamente ao campo da saúde, por exemplo), mesmo as experiências exitosas com esta perspectiva ganham caráter pretérito e até mesmo de inconformidade com a lei, após a provável implantação desse novo ensino médio. Muitas experiências locais, do chão da escola, assim, serão desconsideradas sem que todas as suas

10 http://www.brasil.gov.br/educacao/2016/10/anuncios-publicitarios-explicam-mudancas-propostas-pelo-novo-ensino-medio

11 A comissão mista destinada a examinar a Medida Provisória 746/2016 que reestrutura o ensino médio aprovou, no dia 30/11/2016, o substitutivo do relator, senador Pedro Chaves (PSC-MS), que reinclui artes e educação física como componentes curriculares obrigatórios - Projeto de Lei de Conversão (PLV) 34/2016. Disponível em < http://www.camara.gov.br/proposicoesWeb/fichadetramitacao?idProposicao=2112490 > 
potências tenham sido reveladas, sem que fossem devidamente inventariadas, visibilizadas e credibilizadas.

A emergência dessa política, e das que economicamente as justificam, nos colocam metaforicamente diante de um "cerco", e tal qual o uso semântico de Saramago no livro que nos inspira, representa severa limitação aos princípios democráticos e crítico-progressistas que ainda víamos como esperança para melhorar a qualidade da educação nacional, mesmo a partir de um cenário global reconhecidamente neoliberal. A caracterização que fizemos deste pano de fundo, reconhecemos, também é esta uma das narrativas possíveis a engendrar o que pode ser tornado histórico a partir da leitura deste contexto. Este, portanto, é o limite do cenário de onde buscamos "vasculhar", entender e propor condições de atuação. É contra este cerco que sugerimos a "história do não", uma história prática e de horizontes poéticos também a nós professores. Sustentar a potência de outras matrizes narrativas, portanto, é o que nos concerne para a escrita deste texto. Isso se deve basicamente a nossa profunda inconformidade com o curso das políticas educativas contemporâneas no espectro do cenário educativo brasileiro.

Embora hoje ainda não estejamos, na condição de professores, a executar esses eventuais novos endereçamentos (pois são projetos de lei em tramitação), os sentimentos de consternação e de desalento já parecem pairar sobre o professorado. Vivemos no dia a dia da escola acompanhando as inúmeras e desencontradas informações que nos chegam a respeito das "novas políticas", com um misto de incredulidade e de resignação quanto ao assujeitamento que essas devem vir a provocar em nossos cotidianos. São políticas educativas planejadas e em vias de serem implantadas de modo arbitrário, recuperando fórmulas já testadas e superadas, que desconsideram os debates e as caminhadas que a comunidade acadêmica e a sociedade civil em conjunto galgavam, formalizadas como políticas públicas nos últimos vinte anos. Acompanhamos, aflitos, as eventuais imposições aos nossos jeitos de ser e agir nas escolas, como se, em nossa paragem vislumbrássemos um horizonte intempestivo a se mover em nossa direção, a conjurar um cenário perspectivo devastador, onde, aparentemente, admiraremos o que fomos, sofreremos pelo que somos e lamentaremos o infortúnio do que não seremos.

Entendemos, assim, que mais do que compreendermos esse processo em andamento, forjando uma história possível deste tempo presente, é preciso, politicamente, assumir estratégias para, mais do que denunciar, empoderar os agentes que lutam em espaços locais. Isso também significa dizer, que os "Raimundos e as Raimundas" da história, precisam ganhar visibilidade, não só escreverem suas histórias a respeito deste e de outros cercos passados, mas que estas ganhem outros leitores e assim, outras ressonâncias hermenêuticas. Os auspícios da pesquisa narrativa, conforme a concebemos e descrevemos, podem por em evidência experiências de nãos que foram ditos e corporificados ante as políticas educativas residuais ao longo do tempo, criando enfrentamentos narrativos diversos. Entendemos que o primeiro e necessário não a ser dito é ao que simplesmente deslegitima e enfraquece a educação física como componente curricular obrigatório no ensino médio, seguido por outros tantos que reforçariam o protagonismo dos professores ao longo de suas carreiras.

Os estudos narrativos, segundo Clandinin e Connelly (2011), à medida que podem vir a se tornar textos literários, ao serem lidos e credibilizados por outros que vivem ou viveram em tempos e contextos semelhantes, servem como testes vicários de possibilidades, ampliando 
a conexão educativa da vida, da literatura e do ensino, criando tensões com as narrativas dominantes.

\section{DA PESQUISA NARRATIVA À APRENDIZAGEM NARRATIVA: ELEMENTOS PARA "DIZER NÃO" (E UM POUCO MAIS) AO CURSO CRONOLÓGICO DA CONSTRUÇÃO DA HISTÓRIA}

Neste ensaio nos dedicamos a apresentar uma proposição teórica em que articulamos os fundamentos da pesquisa narrativa com as premissas do modelo de história como narrativa (RICOEUR, 2010a) e de história a contrapelo (BENJAMIN, 2013), como forma de compreender e enfrentar o processo de implantação das políticas educativas contemporâneas. Essa bricolagem teórica e metodológica (KINCHELOE, 2007) parte da ideia de que é possível contestar esses acontecimentos, abrindo cesuras na história, tornando-a permeada de constelações críticas (BENJAMIN, 2013), de arranjos compostos por experiências narradas por personagens normalmente desvalidos de importância pela grande história.

Esse processo culminaria em oferecer aos professores colaboradores com estudos sob essa orientação, uma aprendizagem narrativa (GOODSON; GILL, 2011). Segundo esses autores, essa aprendizagem se dá quando o sujeito, ao narrar sua experiência, integra turnos do passado com o presente, faz dialogantes os episódios recuperados pela memória e as suas atuais crenças e valores de ordem pessoal e profissional. Se perfaz, assim, em uma relação intimamente temporal da narrativa com a vida, onde as experiências passadas e presentes se coadunam para formular e viabilizar projetos e perspectivas futuras. Esse inventário crítico de experiências possui um potencial ainda pouco mensurável, mas, a nosso ver, reúne condições de nos tornar, na qualidade de pesquisadores, e os professores em seus lócus, Raimundos e Raimundas habilitados, se não a mudar definitivamente o curso da história, a de compreender e atuar sob os "cercos" impostos pelas políticas educativas contemporâneas.

A narração dessas novas e incontáveis histórias permitiriam aos professores se reconhecerem dizendo, organizando elementos que até então operavam, mas não significavam o que, em tese, poderá permitir empreender mudanças que alterem as suas realidades em diferentes dimensões e intensidades, forjando alternativas pessoais e coletivas à história. Esse engajamento é bastante reconhecido como possível em estudos como os de Goodson (2013a; 2013b), em que o autor defende a importância do reconhecimento nas investigações acadêmicas historiográficas do capital narrativo dos professores (GOODSON, 2013a), tanto para compreender o processo de implantação das políticas educativas quanto para reconhecer suas capacidades de responder criativamente a essas orientações, nos âmbitos político e pedagógico. De acordo com o pensamento do autor, valorizar o capital narrativo tem potencial revolucionário, pois pode vir a ser "perigoso" dentro de uma reforma político-educativa, à medida que essas vozes geralmente são portadoras de contrapontos, contrasensos e contra-argumentos que complexificam o "sistema de mudança", provocando entropia ou a adoção de um caminho não congruente com o que os formuladores das políticas previam e defendiam.

Partilhamos também do entendimento de White (2014) de que a história não seja vista como simples cimento das nossas subjetivações. É preciso que ela seja prática, que nos ofereça o passado como ferramenta, que nos dê condições de ação, uma poiesis aberta para 
o reconhecimento do que fora silenciado e também a projeção de outros possíveis. A pesquisa narrativa apresenta, no nosso ponto de vista, uma potência de reacender passados e imaginar futuros que a narrativa da história sistêmica não nos permitiria vislumbrar. Exagerado, utópico, pretensioso? Talvez, mas como o mundo que defendemos não está em curso, reside na luta pela narrativa do presente e na arte da criação de alternativas a assunção daquele que ainda queremos e que ainda entendemos ser possível.

É preciso, porém, talvez subvertendo um pouco a lógica do que defendemos até aqui em nosso texto, ir além do não; é preciso avançar ainda um pouco mais quando chegar o momento de podermos dizê-lo. É esse o pensamento de Rüsen (2016), quando afirma que o processo de construção da história precisa, além de prover narrativas que a critiquem, também oferecer condições a quem narra para que seja possível compreender a temporalidade de modo mais complexo. Uma nova consciência histórica demandaria e dependeria, dessa forma, de uma narrativa genética (RÜSEN, 2016), capaz de possibilitar um novo estado das coisas, em que os sujeitos seriam capazes de ajustar as suas vidas de modo a melhor lidarem com os desafios da temporalidade. Ela provocaria, em outra extensão, um ajuste do homem a sua própria história nos diferentes espectros do tempo - passado, presente e futuro. A narrativa genética, segundo o autor, viria a ensinar que as alterações das formas de vida produzem permanências, uma identidade, e é ela que fundamentalmente poderá vir a garantir que as forças das mudanças resistam as estabilidades. Nosso entendimento, assim, é de que tanto o passado quanto a história devem ser demovidos de uma essência metafísica para se tornarem conceitos operativos, dos quais os indivíduos se valham, afirmando e encontrando espaço para a sua palavra; que eles possam se ver, se identificar e se reinscrever como protagonistas-críticos de versões mais complexas, quiçá revolucionárias, da história e de si mesmos.

Desse cenário, das experiências e aprendizagens que as narrativas são capazes de oferecer, acreditamos ser possível criar outra realidade para a construção da história das políticas educativas dirigidas ao professorado de Educação Física. Uma história em que os desígnios dos ordenamentos legais sejam compreendidos em sua temporalidade, na identidade que esta produziu nos sujeitos. Em nossas intensidades críticas estão as chaves e os motores das nossas aprendizagens e experiências, atuais e futuras. Elas estão pujantes nas narrativas contadas e pouco ouvidas, nas subjetividades dos narradores preteridos, jazem na pré-narrativa vivida apenas no traiçoeiro e nem sempre confiável refúgio da memória. Não se trata de ser redentor; se trata de ser escritor, e como tal acreditar que por trás de cada nova história, reside um novo mundo, vivendo e pulsando em outros imaginários registros. Um mundo que assim permanecerá, pelo menos até que tenhamos condições de a alguém contá-lo, revelando assim um novo olhar para o que vivíamos e uma projeção inesperada e inesgotável ao que se abre. Faz-se assim o convite aos possíveis, a trabalharmos para a construção de literaturas que se pretendam históricas, habitáveis por quem escreve e quem por ventura queira sempre reescrevê-las. Seriamos nós, ao mesmo tempo, Raimundos e Saramagos, a história e a caneta, a produzir e produzir-se, cercos e escritores das narrativas que aprendemos e ensinamos 


\section{REFERÊNCIAS}

APPLE, Michael W. Política cultural e educação. São Paulo: Cortez, 2000.

APPLE, Michael W. Educando à Direita: mercados, padrões, Deus e desigualdade. São Paulo: Cortez: Instituto Paulo Freire, 2003.

BENJAMIN, Walter. 0 anjo da história. 2.ed. Belo Horizonte: Autêntica, 2013.

BALL, Stephen. Educational reform: a critical and post-structural approach. Buckingham: Open University, 1994.

BRASIL. Ministério da Educação. Lei no 9.394 de 20 de dezembro de 1996. Lei de Diretrizes e Bases da Educação Nacional. Disponível em: <http://www.planalto.gov.br/ccivil 03/leis/L9394.htm>. Acesso em: 15 Dez. 2016.

BRASIL. Secretaria de Educação Fundamental. Parâmetros curriculares nacionais: Educação Física. Brasília: 1998a. Disponível em: < http://portal.mec.gov.br/seb/arquivos/pdf/livro07.pdf >. Acesso em: 17 Dez. 2016.

BRASIL. Resolução CEB № 3, Institui as Diretrizes Curriculares Nacionais para o Ensino Médio. Diário Oficial da República Federativa do Brasil, Brasília, DF, 5 ago. 1998b. Disponível em: < http:// portal.mec.gov.br/cne/arquivos/pdf/rceb03_98.pdf>. Acesso em: 15 Dez. 2016.

BRASIL. Ministério da Educação. Orientações curriculares do ensino médio. Brasília, DF, 2004. Disponível em: <http://portal.mec.gov.br/seb/arquivos/pdf/book volume 01 internet.pdf>. Acesso em: 16 Dez. 2016.

BRASIL. Conselho Nacional de Educação (CNE). Resolução n.2, de 30 de Janeiro de 2012. Institui as Diretrizes Curriculares Nacionais para o Ensino Médio. Diário Oficial da República Federativa do Brasil, Brasília, DF, 31 jan. 2012. Disponível em: < http://pactoensinomedio.mec.gov.br/images/pdf/ resolucao_ceb_002_30012012.pdf>. Acesso em: 15 Dez. 2016.

BRASIL. Ministério da Educação. Base Nacional Curricular Comum. Brasília, DF, 2015. Disponível em: <http://basenacionalcomum.mec.gov.br/\#/site/interaja?ac=AC CIH>. Acesso em: 20 Jan. 2017.

BRASIL. Ministério da Educação. Base nacional Curricular Comum. Brasília, DF, 2016a Disponível em: <http://basenacionalcomum.mec.gov.br/documentos/bncc-2versao.revista.pdf >. Acesso em: 20 jan. 2017.

BRASIL. Medida Provisória no 746, de 22 de Setembro de 2016. Institui a Política de Fomento à implementação de Escolas de Ensino Médio em Tempo Integral [...] e dá outras providências. Diário Oficial da União. 2016b. Disponível em: <http://www.planalto.gov.br/ccivil 03/ ato2015-2018/2016/ Mpv/mpv746.htm >. Acesso em: 10 Jan. 2017.

CLANDININ, Jean; CONNELLY, Michael. Pesquisa narrativa: experiência e história em pesquisa qualitativa. Uberlândia: EDUFU, 2011.

DELGADO, Lucilia de Almeida; FERREIRA, Marieta de Moraes (orgs.). História do tempo presente. Rio de Janeiro: FGV, 2014.

FARGE, Arlette. Lugares para a História. Belo Horizonte: Autêntica, 2015.

FERREIRA, Marieta de M.; AMADO, Janaína. Usos e abusos da história oral. 8.ed. Rio de Janeiro: FGV, 2006. 
FRIGOTTO, Gaudêncio. Política e gestão educacional na contemporaneidade. In: FERREIRA, Elisa Bartolozzi; OLIVEIRA, Dalila Andrade (orgs.). Crise da escola e políticas educativas. 2.ed. Belo Horizonte: Autêntica, 2013.

GAGNEBIN, Jeanne-Marie. Prefácio. Walter Benjamin ou a história aberta. In: BENJAMIN, Walter. Magia e técnica, arte e política: ensaios sobre literatura e história da cultura. Obras Escolhidas. 8.ed. São Paulo: Brasiliense, 2012. v.1, p. 7-19.

GAGNEBIN, Jeanne-Marie. História e narração em Walter Benjamin. 2.ed. São Paulo: Perspectiva, 2013.

GONZÁLEZ, Fernando Jaime; FENSTERSEIFER, Paulo Evaldo. Entre o "não mais" e o "ainda não": pensando saídas do não-lugar da EF escolar I. Cadernos de formação RBCE, v. 1, n. 1, p. 9-24, 2009.

GOODSON, Ivor; GILL, Scherto R. Narrative Pedagogy: life history and learning. New York: Peterlang, 2011.

GOODSON, Ivor. As políticas de currículo e de escolarização. 2.ed. Petrópolis: Vozes, 2013a.

GOODSON, Ivor. Developing narrative theory: life histories and personal representation. Oxon: Routledge, 2013b.

HERNANDEZ, Fernando et al. Aprendendo com as inovações nas escolas. Porto Alegre: Artes Médicas, 2000.

KINCHELOE, Joe. Redefinindo e Interpretando o Objeto de Estudo. In: KINCHELOE, Joe L.; BERRY, Kathlenn S. Pesquisa em Educação: conceituando a bricolagem. Porto Alegre: Artmed, 2007. p. 101122.

LIBÂNEO, José Carlos; OLIVEIRA, João Ferreira; TOSCHI, Mirza Seabra. Educação Escolar: políticas, estrutura e organização. 8.ed. São Paulo: Cortez, 2009.

MAINARDES, Jefferson. Abordagem do ciclo de políticas: uma contribuição para a análise de políticas educacionais. Educação \& Sociedade, v. 27, n. 94, p. 47-69, jan./abr. 2006.

McCARTHY, Cameron; PITTON, Viviana; KIM, Soochul; MONJE, David. Movimento e estase na reorientação neoliberal da educação. In: APPLE, Michael; AU, Wayne; GANDIN, Luís Armando (Orgs.). Educação Crítica: análise internacional. Porto Alegre: Artmed, 2011. p. 49-65.

PELLAUER, David. Compreender Ricoeur. 2.ed. Petrópolis: Vozes, 2010.

RICOEUR, Paul. Tempo e narrativa 1: a intriga e a narrativa histórica. São Paulo, WMF Martins Fontes, 2010a.

RICOEUR, Paul. Tempo e narrativa 3: o tempo narrado. São Paulo: WMF Martins, 2010b.

RIO GRANDE DO SUL. Proposta Pedagógica no 1, de 2011. Proposta Pedagógica para o Ensino Médio Politécnico e Educação Profissional Integrada ao Ensino Médio. Disponível em: <http:// www.educacao.rs.gov.br/dados/ens_med_proposta.pdf>. Acesso em: 17 dez. 2015.

ROBERTSON; Susan L.; DALE, Roger. O Banco Mundial, o FMI e as possibilidades de educação crítica. In: APPLE, Michael; AU, Wayne; GANDIN, Luís Armando (orgs.). Educação Crítica: análise internacional. Porto Alegre: Artmed, 2011, p. 34-48. 
RÜSEN, Jörn. Narração histórica: fundações, tipos, razão. In: MALERBA, Jurandir (Org.). História e narrativa: a ciência e a arte da escrita histórica. Petrópolis: Vozes, 2016, p. 45-57.

SARAMAGO, José. História do cerco de Lisboa. São Paulo: Companhia das Letras, 1989.

SIRINELLI, Jean-François. Abrir a história: novos olhares sobre o século XX francês. Belo Horizonte: Autêntica, 2014.

VEYNE, Paul M. Como se escreve a história: Foucault revoluciona a história. 4.ed. Brasília: Editora Universidade de Brasília, 2014.

WHITE, Hayden. Practical Past. Chicago: Northwestern University, 2014.

WITTIZORECKI, Elisandro et al. Pesquisar exige interrogar-se: a narrativa como estratégia de pesquisa e formação do(a) pesquisador(a). Movimento, v.12, n.2, p.9-33, maio/ago. 2006. Disponível em: <http://www.seer.ufrgs.br/index.php/Movimento/article/view/2904/1540>. Acesso em 10 Dez. 2016. 
